\title{
CORRECTION
}

\section{Correction to: Prevalence of Triad-RED-S symptoms in high-level Kenyan male and female distance runners and corresponding control groups}

\author{
Lauri Õnnik $^{1}$ - Martin Mooses ${ }^{1} \cdot$ Silva Suvi $^{1} \cdot$ Diresibachew W. Haile $^{2,3} \cdot$ Robert Ojiambo $^{2,4} \cdot$ Amy R. Lane $^{5}$.
} A. C. Hackney ${ }^{5}$

Published online: 24 October 2021

(c) Springer-Verlag GmbH Germany, part of Springer Nature 2021

\section{Correction to: European Journal of Applied Physiology https://doi.org/10.1007/s00421-021-04827-w}

The original version of this article unfortunately contained a mistake. Author name Diresibachew W. Haile was incorrectly written as Diresibashew W. Haile.

Publisher's Note Springer Nature remains neutral with regard to jurisdictional claims in published maps and institutional affiliations.

The original article can be found online at https://doi.org/10.1007/ s00421-021-04827-w.

\section{Lauri Õnnik}

lauri.onnik@ut.ee

1 University of Tartu, Ujula 4, 51008 Tartu, Estonia

2 Moi University, Eldoret, Kenya

3 Addis Ababa University, Addis Ababa, Ethiopia

4 University of Global Health Equity, Butaro, Rwanda

5 University of North Carolina, Chapel Hill, NC, USA 